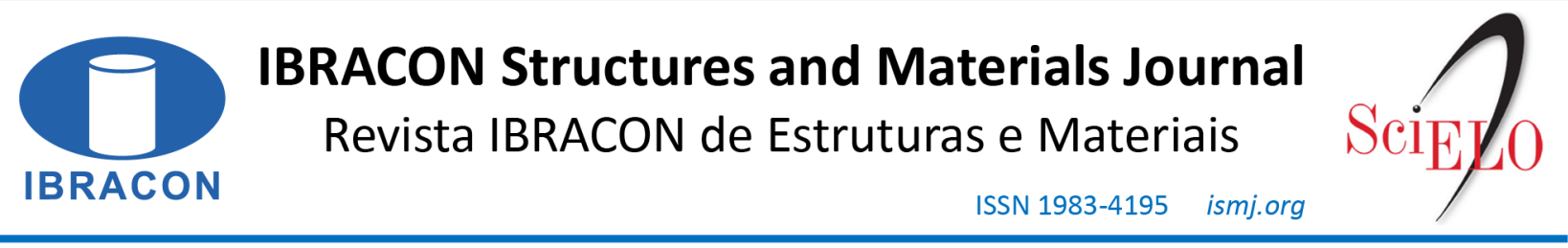

ORIGINAL ARTICLE

\title{
Numerical analysis on displacements of steel-fiber-reinforced concrete beams
}

\section{Análise numérica da deformabilidade de vigas de concreto armado reforçado com fibras}

\author{
Mateus Fereira Pontes ${ }^{\mathrm{a}}$ \\ Wanderlei Malaquias Pereira Junior ${ }^{\mathrm{a}}$ (D) \\ José Júlio de Cerqueira Pituba ${ }^{\mathrm{a}}$ (D)
}

${ }^{a}$ Universidade Federal de Catalão - UFCAT, Departamento de Engenharia Civil, Catalão, GO, Brasil

Received 19 June 2018

Accepted 15 March 2020

\begin{abstract}
This work deals with parametric analyses of the structural behaviour of steel-fiber-reinforced concrete using a Damage Constitutive Model and homogenization technique. This approach is contemporary once Brazil has not a standard procedure for the design of this type of material. The present study performs a parametric analysis of rectangular beams subjected to flexion at four points, with height variations (h), reinforcement area (As) and span (L) are used to verify the influence of each parameter on the numerical study of the deformability of beams composed by this material. Fiber volume concentrations of $2.00 \%$ and $2.50 \%$ have been used on the modelling. It is observed that the obtained results were mainly affected by height and span. It is noticeable that the inclusion of steel fibers leads to an increase in the maximum load and ductility of the analyzed beams in this work.
\end{abstract}

Keywords: steel-fiber-reinforced concrete, damage mechanics, non-linear analysis, parametric analysis.

\begin{abstract}
Resumo: Este trabalho aborda uma análise numérica paramétrica do comportamento estrutural do concreto armado reforçado com fibras metálicas utilizando um modelo constitutivo de Mecânica do Dano e técnica de homogeneização. Essa abordagem ainda é recente, visto que o Brasil não possui nenhuma normatização em relação ao procedimento de cálculo desse tipo de material. O presente estudo realiza uma análise paramétrica de vigas de seção retangular submetidas à flexão em quatro pontos com variações de altura (h), área de aço (As) e o vão (L) de forma a verificar a influência de cada parâmetro no estudo numérico da deformabilidade de vigas compostas por esse material. Foram utilizados percentuais de 2,00\% e 2,50\% de fibras metálicas na modelagem. Observa-se que os resultados obtidos foram afetados principalmente pela altura e pelo vão da peça. Também se percebe que a inclusão de fibras proporciona aumento da carga máxima da estrutura além de promover uma boa ductilidade.
\end{abstract}

Palavras-chave: concreto reforçado com fibras de aço, mecânica do dano, análise não-linear, identificação paramétrica.

How to cite: M. F. Pontes, W. M. Pereira Junior, and J. J. C. Pituba, "Numerical analysis on displacements of steel-fiber-reinforced concrete beams," Rev. IBRACON Estrut. Mater., vol. 13, no. 6, e13607, 2020, https://doi.org/10.1590/S1983-41952020000600007

\section{INTRODUCTION}

Concrete is one of the most used materials as a constituent of structural elements [1], [2] and due to its great importance, several numerical models are developed to simulate its mechanical behaviour [3].

In several situations there is a need for the concrete to resist tensile and bending loads, making it necessary to use longitudinal and transverse reinforcements. However, new ways of using this material have been developed, as example, the use of metallic fibers in simple and reinforced concrete. Salvador et al. [4] says that metal fibers have 
been used for a long time and can be considered a kind of traditional reinforcement for concrete. Despite this, there are several technical aspects of this kind of reinforcement that still need a better study.

In Brazil, fiber reinforced concrete is still a material not so used in civil construction and it deserves more studies for understanding its behaviour. Only two Technical Standards address the theme: (a) NBR 15530 "Steel fibers for concrete specification" [5]; and (b) NBR 8890 "Circular section concrete pipe for rainwater and sanitary sewerage systems Requirements and test methods" [6]. Despite this national reality, in other countries this material already has great applicability in Structural Engineering, for example, in shotcrete for tunnels, earthquakes regions, slender repairs, pavements subjected to dynamic loads, in the area of structural recovery, rigid pavements subjected to cyclic loads [7]-[11] including technical standards which guide tests and design steps, such as the following codes: ACI 544.1R-96 [12], ACI 544.2R-89 [13], ACI 544.3R-93 [14], ACI 544.4R-88 [15], ACI 318 [16], RILEM TC 162-TDF [17], Model Code 2010 [18] and EN 14651 [19]. The study of this material is still an open research field, especially concerning the computational modelling line of structural parts composed of this material.

Banthia and Trottier [20] recommend the use of fibers in order to improve the mechanical properties of composite materials. Therefore, in this context, the incorporation of fibers of different natures into concrete deserves to be highlighted. However, in this work, the goal is to contribute on the understanding of the mechanical behaviour of concrete beams reinforced with steel fibers. In this context yet [21], made an analysis of the recent advances in the area of Ultra High-Performance Fiber-Reinforced Concrete (UHPFRC) leading to the conclusion that the current regulations are not valid to be used in the design of structural elements composed of this kind of material. Also Buttignol et al. [21], discusses some normative issues related to its properties, such as bending, compression, stress-strain relations, design criteria, etc. In Błaszczyński and Falek [22], the addition of short metal fibers in concrete samples subjected to uniaxial compression tests has been investigated. The experimental tests indicated that for additions of $0.50 \%$ and $3.00 \%$ there was an increasing of tension strength on the tested samples. Specifically, the control concrete with $0.00 \%$ of fibers showed a peak tension of $35.88 \mathrm{MPa}$ while the samples with $3.00 \%$ of fiber reached values about $41.99 \mathrm{MPa}$. In Yoo et al. [23], concrete beams with Ultra High-Performance Concrete (UHPC) have been investigated numerically and experimentally. Beams with a fiber ratio between $0.00 \%$ (beam with control concrete) and $1.71 \%$ fibrous reinforcement were tested. It has been concluded that for steel fiber reinforced beams, an increasing in the post-peak region as well as a toughness gain have been observed.

In this context, the intention of the present work is to contribute for understanding the mechanical behaviour of steel-fiber-reinforced concrete beams the influence of a cementitious matrix and fibers in the load peak of beams. Therefore, the present work can be justified due to importance of the theme and the need of more researches about.

Regarding the investigation of the applicability of constitutive models for cracked concrete, there are several numerical tools which stand out, including the following: (a) Continuum Damage Mechanics (CDM) Models [3], [24]-[30]; (b) Concentrated Damage Model [31]-[36]; (c) Cracking distributed [37]-[40]; (c) Multi-scale models [41]; (d) Models based on failure or rupture criteria [28], [42]; and (e) Fracture models [28], [43]. On the other hand, the models can be called phenomenological models, which are intended to model the mechanical behaviour of materials based on dissipative processes which occur in the microscale. On the other hand, the so-called multiscale models have been gaining attention in recent years. In this case, the mechanical behaviour of the macroscale is a consequence of the dissipative processes of the microscale leading to a more realistic representation of the nonlinear physical behaviour of materials. This modelling is possible due to the use of homogenization techniques. However, the computational cost is still a limiting factor in some more complex analyses. Within this context, it can be cited some works that deals with concrete with fibers [44]-[46].

The constitutive damage model developed by Pituba and Fernandes [26] together with a homogenization process proposed by La Borderie [47] are used in the present work to consider the incorporation of steel fibers into the concrete. This method has already been applied and discussed initially in Pereira et al. [3].

In this paper, the model will be used to investigate the mechanical behaviour of steel-fiber-reinforced concrete (SFRC) beams focusing on the deformability aspects in order to contribute to a proposal for estimating displacements in SFRC beams in a future expansion of NBR 6118 [48] dealing with SRFC.

On the other hand, CDM is a constitutive theory that simulates the degradation of the elastic properties of the material as a cause of the cracking processes. Therefore, it is a properly theory for materials which present the cracking process as an important phenomenon of physical non-linearity, such as concrete. CDM seeks to describe a local constitutive relationship that changes the material stiffness from an early stage, considering a situation without defects, to the situation of complete damage of the Representative Volume Element (RVE). 
Therefore, this work aims to contribute for understanding the mechanical behaviour of concrete with fibers and to identify parameters which support a discussion on the context of a future proposal for the standardization of this material.

This work is divided into 5 sections. In the first one, a brief introduction to the topic is presented. In section 2, the formulation of the damage model employed is briefly addressed, as well as the concepts of the proposed homogenization are presented. The presentation of the object of study of the numerical analyses ends section 2 . The numerical examples are presented in section 3. Finally, sections 4 and 5 present the obtained results as well as the conclusions and suggestions for further work.

\section{CONSTITUTIVE MODEL FOR CONCRETE AND CONCRETE WITH FIBERS}

In this section, the necessary tools to perform the numerical analyses are presented, as well as the finite element models of the objects of study in this work. Initially, the damage model for concrete and the homogenization model are briefly addressed for the consideration of steel fibers incorporated into concrete. Then, the finite element model and the numerical analyses performed are presented.

\subsection{Constitutive Damage Model}

Concrete is understood here as a material that belongs to the category of initially isotropic media that starts to present transverse isotropy and bimodular response induced by damage. The formulation of the model for concrete is based on the energy equivalence principle and the formalism has been presented in Pituba and Fernandes [26]. In what follows, the proposed model is briefly described, starting with the presentation of the damage tensor for predominant states of traction, whose expression is given in the form:

$$
D_{T}=f_{l}\left(D_{1}, D_{4}, D_{5}\right)(A \otimes A)+2 f_{2}\left(D_{4}, D_{5}\right)[(A \underline{\bar{\otimes}} I+I \underline{\bar{\otimes}} A)-(A \otimes A)]
$$

where $f_{l}\left(D_{1}, D_{4}, D_{5}\right)=D_{1}-2 f_{2}\left(D_{4}, D_{5}\right)$ and $f_{2}\left(D_{4}, D_{5}\right)=1-\left(1-D_{4}\right)\left(1-D_{5}\right)$.

The damage tensor has two scalar variables in its composition $\left(D_{l}\right.$ and $\left.D_{4}\right)$ and a third damage variable $D_{5}$, activated only if there has been a previous compression with corresponding damage. The variable $D_{l}$ represents the damage in the direction perpendicular to the local plane of transversal isotropy of the material and $D_{4}$ is the variable representing the damage generated by the shear between the edges of the cracks belonging to that plane.

In Equation 1, tensor $\boldsymbol{I}$ is the second order identity tensor and tensor $\boldsymbol{A}$ is, by definition, formed by the tensor product of the versor perpendicular to the transverse isotropy plane itself. The tensor product operations between second order $\boldsymbol{I}$ and $\boldsymbol{A}$ tensors that appear in Equation 1 and that will be used throughout the formulation are described in Pituba and Fernandes [26].

For predominant states of compression, the relation for the damage tensor is proposed:

$$
D_{C}=f_{I}\left(D_{2}, D_{4}, D_{5}\right)(A \otimes A)+f_{2}\left(D_{3}\right)[(I \bar{\otimes} I)-(A \otimes A)]+2 f_{3}\left(D_{4}, D_{5}\right)[(A \underline{\bar{\otimes}} I+I \underline{\otimes} A)-(A \otimes A)]
$$

where $f_{1}\left(D_{2}, D_{4}, D_{5}\right)=D_{2}-2 f_{3}\left(D_{4}, D_{5}\right), f_{2}\left(D_{3}\right)=D_{3}$ and $f_{3}\left(D_{4}, D_{5}\right)=1-\left(1-D_{4}\right)\left(1-D_{5}\right)$.

There are three scalar variables in its composition: $D_{2}, D_{3}$, and $D_{5}$, in addition to $D_{4}$, related to pre-existing traction effects. The variable $D_{2}$ (damage perpendicular to the local plane of transversal isotropy of the material) penalizes the elastic modulus in this direction, and together with $D_{3}$ (representative of damage in the transversal isotropy plane) penalizes the Poisson's ratio in planes perpendicular to the transversal isotropy one.

Finally, the resulting constitutive tensors are described by:

$$
E_{T}=\lambda_{I I}[I \otimes I]+2 \mu_{1}[I \underline{\bar{\otimes}} I]-\lambda_{22}^{+}\left(D_{1}, D_{4}, D_{5}\right)[A \otimes A]-\lambda_{12}^{+}\left(D_{I}\right)[\mathbf{A} \otimes \mathbf{I}+\mathbf{I} \otimes \mathbf{A}]-\mu_{2}\left(D_{4}, D_{5}\right)[A \underline{\bar{\otimes}} I+I \underline{\bar{\otimes}} A]
$$


$E_{C}=\lambda_{11}[I \otimes I]+2 \mu_{1}[I \underline{\otimes} I]-\lambda_{22}^{-}\left(D_{2}, D_{3}, D_{4}, D_{5}\right)-\lambda_{12}^{-}\left(D_{2}, D_{3}\right)$

$[\mathbf{A} \otimes \mathbf{I}+\mathbf{I} \otimes \mathbf{A}]-\lambda_{11}^{-}\left(D_{3}\right)[\mathbf{I} \otimes \mathbf{I}]-\frac{\left(1-2 v_{0}\right)}{v_{0}} \lambda_{I I}^{-}\left(D_{3}\right)[\mathbf{I} \otimes \mathbf{I}]-\mu_{2}\left(D_{4}, D_{5}\right)[A \underline{\otimes} I+I \underline{\otimes} A]$

where $\lambda_{11}=\lambda_{0}$ and $\mu_{1}=\mu_{0}$. The other parameters exist only for non-zero damage, thus showing the anisotropy and bimodularity induced by the damage, and are defined by:

$\lambda_{22}^{+}\left(D_{1}, D_{4}, D_{5}\right)=\left(\lambda_{0}+2 \mu_{0}\right)\left(2 D_{1}-D_{1}^{2}\right)-2 \lambda_{12}^{+}\left(D_{1}\right)-2 \mu_{2}\left(D_{4}, D_{5}\right) \quad \lambda_{12}^{+}\left(D_{1}\right)=\lambda_{0} D_{1} ;$
$\mu_{2}\left(D_{4}, D_{5}\right)=2 \mu_{0}\left[1-\left(1-D_{4}\right)^{2}\left(1-D_{5}\right)^{2}\right]+\frac{\left(v_{0}-1\right)}{v_{0}} \lambda_{11}^{-}\left(D_{3}\right)-2 \mu_{2}\left(D_{4}, D_{5}\right)$
$\lambda_{12}^{-}\left(D_{2}, D_{3}\right)=\lambda_{0}\left[\left(1-D_{3}\right)^{2}-\left(1-D_{2}\right)\left(1-D_{3}\right)\right] \lambda_{11}^{-}\left(D_{3}\right)=\lambda_{0}\left(2 D_{3}-D_{3}^{2}\right) ; \mu_{2}\left(D_{4}, D_{5}\right)=2 \mu_{0}\left[1-\left(1-D_{4}\right)^{2}\left(1-D_{5}\right)^{2}\right]$

Moreover, Pituba and Fernandes [26] defines a hypersurface in the space of stresses or deformations. This hypersurface is used as a criterion for the identification of the constitutive responses of compression or tension. In this model, a particular shape is adopted for the hypersurface in the deformation space: a hyperplane $g(\varepsilon)$, characterized by its unitary normal $\mathrm{N}(\|\mathrm{N}\|=1)$. For this model, the following relation is valid:

$g\left(\mathbf{e}, \mathbf{D}_{\mathbf{T}}, \mathbf{D}_{\mathbf{C}}\right)=\mathbf{N}\left(\mathbf{D}_{\mathbf{T}}, \mathbf{D}_{\mathbf{C}}\right) \cdot \mathbf{e}_{\mathbf{e}}=g_{1}\left(D_{1}, D_{2}\right) \varepsilon_{V}^{e}+g_{2}\left(D_{1}, D_{2}\right) \varepsilon_{11}^{e}$

where $\gamma_{1}\left(D_{1}, D_{2}\right)=\left\{1+H\left(D_{2}\right)\left[H\left(D_{1}\right)-1\right]\right\} \eta\left(D_{1}\right)+\left\{1+H\left(D_{1}\right)\left[H\left(D_{2}\right)-1\right]\right\} \eta\left(D_{2}\right)$ and $\gamma_{2}\left(D_{1}, D_{2}\right)=D_{1}+D_{2}$.

The Heaveside functions employed in the last relation are given by:

$H(D i)=1$ for $D i>0 ; H(D i)=0$ for $D i=0(i=1,2)$

The functions $\eta\left(D_{1}\right)$ and $\eta\left(D_{2}\right)$ are defined, respectively, for traction cases, assuming that there is no prior damage to compression, and compression, assuming that there was no prior damage to traction.

$\eta\left(D_{1}\right)=\frac{-D_{1}+\sqrt{3-2 D_{1}^{2}}}{3} ; \eta\left(D_{2}\right)=\frac{-D_{2}+\sqrt{3-2 D_{2}^{2}}}{3}$

Regarding the damage criterion, it is convenient to separate it into a criterion for the beginning of damage, when the material is no longer isotropic; and criteria for loading and unloading, being understood here in the sense of evolution or not of the damage variables when the material is already presented as transversely isotropic.

The criterion for initial damage processes activation in tension or compression is given by:

$f_{T, C}(s)=W_{e}^{*}-Y_{O T, 0 C}<0$

where $W_{e}^{*}$ is the complementary elastic deformation energy considering the initially intact, isotropic and purely elastic environment and $Y_{O T}=\frac{\sigma_{0 T}^{2}}{2 E_{0}}$ ou $Y_{O C}=\frac{\sigma_{O C}^{2}}{2 E_{0}}$ is a reference value obtained from uniaxial tensile or compression tests, respectively, where $\sigma_{O T}$ and $\sigma_{O C}$ stresses of the elastic limits.

Therefore, $D_{T}=0$ (that is, $D_{1}=D_{4}=0$ ) for predominant states of traction or $D_{C}=0$ (that is, $D_{2}=D_{3}=D_{5}=0$ ) for compression states, where the material response regime is linear elastic and isotropic. 
For $g\left(\varepsilon, D_{T}, D_{C}\right)>0$, the complementary elastic energy of the damaged environment is given by the relation:

$$
W_{e+}^{*}=\frac{\sigma_{11}^{2}}{2 E_{0}\left(1-D_{1}\right)^{2}}+\frac{\left(\sigma_{22}^{2}+\sigma_{33}^{2}\right)}{2 E_{0}}-\frac{v_{0}\left(\sigma_{11} \sigma_{22}+\sigma_{11} \sigma_{33}\right)}{E_{0}\left(1-D_{1}\right)}-\frac{v_{0} \sigma_{22} \sigma_{33}}{E_{0}}+\frac{\left(1+v_{0}\right)}{E_{0}\left(1-D_{4}\right)^{2}\left(1-D_{5}\right)^{2}}\left(\sigma_{12}^{2}+\sigma_{13}^{2}\right)+\frac{\left(1+v_{0}\right)}{E_{0}} \sigma_{23}^{2}
$$

On the other hand, for predominant states of compression $\left(g\left(\varepsilon, \mathrm{D}_{\mathrm{T}}, \mathrm{D}_{\mathrm{C}}\right)<0\right)$, the complementary elastic energy is expressed by:

$$
W_{e-}^{*}=\frac{\sigma_{11}^{2}}{2 E_{0}\left(1-D_{2}\right)^{2}}+\frac{\left(\sigma_{22}^{2}+\sigma_{33}^{2}\right)}{2 E_{0}\left(1-D_{3}\right)^{2}}-\frac{v_{0}\left(\sigma_{11} \sigma_{22}+\sigma_{11} \sigma_{33}\right)}{E_{0}\left(1-D_{2}\right)\left(1-D_{3}\right)}-\frac{v_{0} \sigma_{22} \sigma_{33}}{E_{0}\left(1-D_{3}\right)^{2}}+\frac{\left(1+v_{0}\right)}{E_{0}\left(1-D_{4}\right)^{2}\left(1-D_{5}\right)^{2}}\left(\sigma_{12}^{2}+\sigma_{13}^{2}\right)+\frac{\left(1+v_{0}\right)}{E_{0}} \sigma_{23}^{2}
$$

Considering, then, a general situation of a damaged medium in a predominant traction regime, the damage increases identification criterion is represented by the following relation:

$f_{T}(\sigma)=W_{e+}^{*}-Y_{0 T}^{*} \leq 0$

Where the reference value $Y_{O T} *$ is defined by the maximum complementary elastic energy determined during the damage process up to the current state. For the damaged medium in a predominant compression regime, analogous relationships to the case of traction are valid.

In cases where loading is configured, that is, where $D_{T} \neq 0$ and/or $D_{C} \neq 0$, it is necessary to update the values of the damage scalar variables that appear in the $\mathrm{D}_{\mathrm{T}}$ and $\mathrm{D}_{\mathrm{C}}$, tensors, considering their evolution laws.

Limiting the analysis to the case of increasing monotonic loading and uniaxial version of the model, the proposed laws of evolution for scalar damage variables are the result of adjustments on experimental results. The general form proposed is:

$$
D_{i}=1-\frac{1+A_{i}}{A_{i}+\exp \left[B_{i}\left(Y_{i}-Y_{0 i}\right)\right]} \quad \text { with } i=1,2
$$

Where $A i, B i$, and $Y O i$ are parameters to be identified. The parameters Y0i are understood as initial limits for the activation of the damage, the same used in Equation 10.

There is still a need to define the location of the material local plane of transversal isotropy, therefore, the following statement is accepted as valid: "In the space of the main deformations, if two of the three deformation rates are elongation, shortening or null, the plane defined by them will be the material local plane of transversal isotropy."

Both in the case of uniaxial traction and uniaxial compression, it turns out that the transverse isotropy plane is perpendicular to the direction of the tension or compression stress.

This one-dimensional version of the model was implemented in a finite element code for the analysis of bar structures with layered finite elements. For concrete, the damage model is valid, and for longitudinal reinforcement bars, an elastoplastic behaviour is admitted. In the discretized reinforced concrete cross section, a certain layer may contain steel and concrete. The related layer contains an equivalent elastic modulus and an equivalent inelastic deformation, using the homogenization rule.

On the other hand, adopting direction 1 as the longitudinal direction of the bar, the model relationships in its onedimensional version are summarized below and they are implemented in the computational code described in item 3 .

$$
E:=\left\{\begin{array}{lll}
E_{C} & \text { if } & g\left(\varepsilon, D_{T}, D_{C}\right)<0 \\
E_{T} & \text { if } \quad g\left(\varepsilon, D_{T}, D_{C}\right)>0
\end{array}\right.
$$

$E_{T}=E_{0}\left(1-D_{1}\right)^{2}\left(1-D_{2}\right)^{2}$ 
$E_{C}=E_{0}\left(1-D_{2}\right)^{2}$

$W_{e+}^{*}=\frac{\sigma_{l I}^{2}}{2 E_{0}\left(1-D_{l}\right)^{2}\left(1-D_{2}\right)^{2}} ; W_{e-}^{*}=\frac{\sigma_{l l}^{2}}{2 E_{0}\left(1-D_{2}\right)^{2}}$

$Y_{T}=\frac{\partial W_{e+}^{*}}{\partial D_{l}}=Y_{1} ; \quad Y_{C}=\frac{\partial W_{e-}^{*}}{\partial D_{2}}=Y_{2}$

$Y_{I}=\frac{\sigma_{I I}^{2}}{E_{0}\left(1-D_{I}\right)^{3}\left(1-D_{2}\right)^{2}} ; Y_{2}=\frac{\sigma_{I I}^{2}}{E_{0}\left(1-D_{2}\right)^{3}}$

\subsection{Mechanical behaviour of fibers and the homogenization model for considering steel fibers}

The crack evolution process in concrete or any other brittle material occurs because of changing the tension lines and, consequently, the accumulation of stress in the crack tip region. The addition of steel fibers mitigates this effect, as they act as a transfer bridge for internal stresses in the solid leading to a reduced stress concentration at the crack tip and, consequently, the crack propagation speed.

Throughout the loading process due to the increasing of the load level, the debonding process between fiber and matrix takes place leading to changes of the internal forces transfer mechanics by adhesion to friction. These changes occur when the tangential stresses at the interface of the materials exceed its adhesion strength promoting sliding between the faces. This debonding process causes relative displacements between fiber and matrix (see Figure 1).

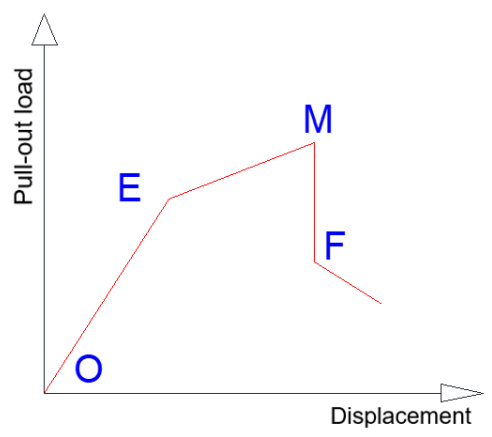

Figure 1. Experimental mechanical behaviour of the fiber/matrix interface behaviour (adapted from Bartos [49]).

In Figure 1, the OE section characterizes all the stress transfers due to adhesion which occur between fiber and concrete, i. e., the displacement of the fiber/matrix interface. At certain loading level, the debonding process represented by EM section is initiated. In this last stage, the process incorporates frictional stresses due to the sliding of the fiber until to the complete debonding represented by MF section. From the F point, the presence of the friction transfer mechanism is remarkable leading to the gradual strength decreasing until the complete pull-out of the steel fiber from the matrix.

A complete analysis of the behaviour should consider the various phenomena related to the mechanical behaviour of the fibers, concrete, and interface. According to La Borderie [47], there are no difficulties in modelling the mechanical behaviour of fibers or concrete. However, the behaviour of the fiber/concrete interface is different from the isolated behaviour of the fiber or concrete.

[47] focused his study on the behaviour of the interface evidenced in pull-out tests of steel fibers from a cementitious matrix. From the observations of the test results, the proposal for uniaxial modelling of the homogenization of the fiber/cement matrix interface behaviour is shown in Figure 2. This proposal was implemented in the finite element code used in Pereira et al. [3]. 


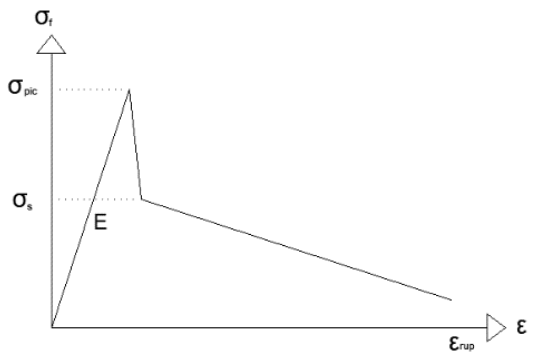

Figure 2. Model for the fiber/matrix interface behaviour (La Borderie [47]).

Figure 2 shows the parameters peak stress $\left(\sigma_{p i c}\right)$, post-peak residual stress $\left(\sigma_{s}\right)$ and limit strain $\left(\varepsilon_{r u p t}\right)$ proposed to represent the fiber/matrix interface behaviour.

On the other hand, using Voigt's kinematic homogenization method [47], proposed the following expression to obtain the homogenized stress:

$$
\sigma_{S F R C}=(1-C) \cdot \sigma_{m}+C \cdot \sigma_{f}
$$

Where: $\sigma_{\text {SFRC }}$ : the homogenized material stress; C: steel fibers concentration; $\sigma_{\mathrm{m}}$ : cementitious matrix stress; $\sigma_{\mathrm{f}}:$ Stress at the fiber/matrix interface.

In Equation 21, the cementitious matrix stress $\sigma_{\mathrm{m}}$ is the result of applying the damage model to the existing concrete in the layers of finite elements, whereas the stress $\sigma_{\mathrm{f}}$ is obtained by applying the model proposed by [47] considering that in the given layer there are fibers immersed in the concrete, this model showed in Figure 2. Finally, applying the homogenization model given by Equation 21, the homogenized material (fibers and concrete) stress for the given layer is obtained.

It is observed that a simplifying hypothesis was introduced: the deformation is assumed to be identical for the matrix and interface. Besides, the fiber orientation, that is random and not aligned to the load direction, is not considered in the proposed modelling. However, for the purposes of this work, it is believed that such limitations have little interference in the numerical results of the concrete structures modelling as the analyses performed are in onedimensional version.

\section{FINITE ELEMENT MODEL}

This item describes the finite element models of beams used to verify the influence of structural element parameters such as height $(h)$, span $(L)$ and the longitudinal reinforcement area $(A s)$ on the estimative of displacements.

The one-dimensional version of the damage model is implemented in a computational code written in FORTRAN language based on the Finite Element Method for the analysis of layered bar elements. The hypothesis of nonconsideration of the distortion deformation is assumed [3]. The mechanical behaviour of the concrete layers is governed by the damage model [26], while the reinforcement inside any layer is governed by a classic bilinear elastoplastic model. If the concrete layer contains fibers (layer characterized as SFRC), the homogenization model proposed by La Borderie [47] is used. Perfect bond between the different materials is assumed with an equivalent longitudinal elastic module and an equivalent inelastic deformation for each layer. For details, see [3], [24]-[26].

The results obtained in this work are based on numerical tests of beams with a rectangular section, where the focus is the analysis of the deformability considering the behaviour of the load versus displacement relationships aiming to contribute to estimate percentages of reduction and/or expansion of the loads and displacements caused by the variation of the geometric parameters of the SFRC beams. The procedure consists in changing parameters of the structural element such as: height (h), span (L) and the longitudinal reinforcement area (As).

The experimental model developed in Lopes [50] has been taken as a reference model for the present work. The initial data of the constitutive models are the same obtained in Pereira et al. [3]. It is important to note that the proposed modelling was used in Pereira et al. [3] to simulate the experimental behaviour obtained by Lopes [50]. Therefore, the modelling of the reference model was validated by Pereira et al. [3] as well as the parametric identifications of the damage and homogenization models. In the present work, the proposed modelling is used varying the geometric parameters of the analysed beams. 
First of all, Figure 3 shows the structural model of the reference beam, when $L=200.00 \mathrm{~cm}, L c=70.00 \mathrm{~cm}, b_{w}=12.50 \mathrm{~cm}$, $h=25.00 \mathrm{~cm}$ and $A_{s}=4.022 \mathrm{~cm}^{2}$. However, these parameters will be varied during the analyses. On the other hand, Figure 4 illustrates the adopted finite element model with 50 finite bar elements and the cross section discretized into 25 layers. In the work [3], a mesh objectivity study was performed, but the finite model does not need finer meshes. Also, the computational cost is considerably low for performing numerical analyses. The reinforcement bars are indicated in Figure 4.

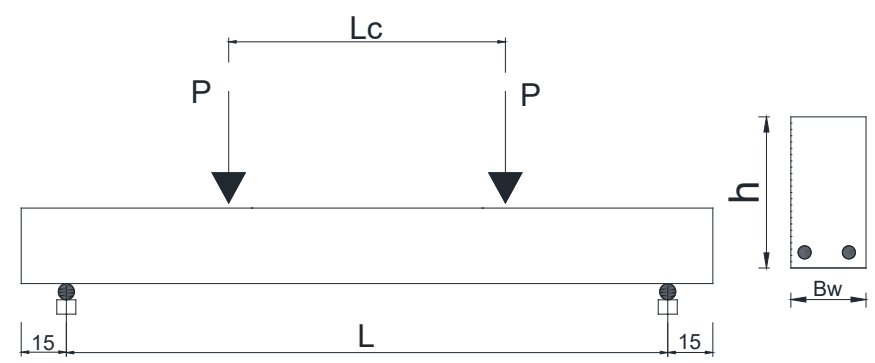

Figure 3. Structural model of the beam proposed for the numerical simulations.
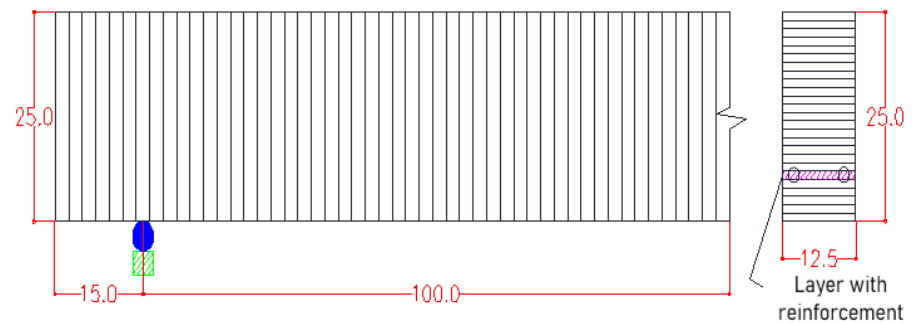

Figure 4. Proposal of finite element mesh for numerical simulations.

Tables 1 and 2 present the values for parameters of the damage and homogenization models considering metallic fibers. The longitudinal reinforcement is CA-50 and its mechanical properties can be seen in Table 3. The results in Tables 1 and 2 have been obtained through retro analysis of four points bending tests performed by Lopes [50] in 100 $\mathrm{mm} \times 100 \mathrm{~mm}$ x $400 \mathrm{~mm}$ specimens with free span of $300 \mathrm{~mm}$. For details, see Pereira et al. [3].

Table 1. Parameters for the damage model proposed in Pituba and Fernandes [26].

\begin{tabular}{ccccccccc}
\hline $\boldsymbol{E}(\boldsymbol{M P a})$ & $\boldsymbol{A}_{t}$ & $\boldsymbol{A}_{\boldsymbol{c}}$ & $\boldsymbol{B}_{\boldsymbol{t}}\left(\boldsymbol{M P a}^{-1}\right)$ & $\boldsymbol{B}_{\boldsymbol{c}}\left(\boldsymbol{M P a}^{-1}\right)$ & $\boldsymbol{Y}_{\boldsymbol{t} t}(\mathbf{M P a})$ & $\boldsymbol{Y}_{\boldsymbol{~} \boldsymbol{c}}(\boldsymbol{M P a})$ & $\boldsymbol{\beta}_{t}$ \\
\hline 31900 & 15 & 0.70 & 1290 & 2.50 & 0.000086 & 0.00455 & 0.00000045 & 0.000030 \\
\hline
\end{tabular}

Table 2. Variables of the homogenization model proposed by La Borderie [47] for the consideration of metallic fibers.

\begin{tabular}{cccc}
\hline Fiber volume percentage $\mathbf{V}_{\mathbf{f}}(\mathbf{\%})$ & Peak Stress (MPa) & Yield stress (MPa) & Ultimate strain (m/m) \\
\hline 2.00 & 525.00 & 420.00 & 0.025 \\
\hline 2.50 & 550.00 & 440.00 & 0.025 \\
\hline
\end{tabular}

Table 3. Parameters values of the elastoplastic model for CA-50 steel for reinforcement.

\begin{tabular}{cccc}
\hline Model properties & Value & Unit & \\
\hline Young's Modulus & $210.000,00$ & $\mathrm{MPa}$ & $\mathrm{MPa}$ \\
\hline Yield strength & 500,00 & $\mathrm{MPa}$ & $\mathrm{kg} / \mathrm{m}^{3}$ \\
\hline Peak stress & 550,00 & $\%$ & $\%$ \\
\hline Specific mass & 7850,00 & 1,00 & $\%$ \\
\hline
\end{tabular}


Note that the numerical analyses have been performed in [24]-[26], [3] validating the use of the proposed damage and homogenization models. On the other hand, the geometric characteristics of the finite element models used in this work are shown in Tables 4 to 6. Considering the "zero" situation as the reference model illustrated in Figure 3, the sequence used in this work is described as follows: (i) Height variation (h) (Table 4); (ii) Variation of the reinforcement area $(A s)$ (Table 5); and (iii) Free span variation $(L)$ (Table 6), respectively.

Table 4. Height variation proposal $(h)$.

\begin{tabular}{cccccc}
\hline Test & h $(\mathbf{c m})$ & $\mathbf{b}(\mathbf{c m})$ & $\mathbf{L}(\mathbf{c m})$ & $\mathbf{A s}\left(\mathbf{c m}^{\mathbf{2}}\right)$ & 4.022 \\
\hline h0 & 25.00 & 12.50 & 230 & 4.022 & 2.00 \\
\hline h1 & 26.25 & 12.50 & 230 & 4.022 & 2.10 \\
\hline h2 & 28.13 & 12.50 & 230 & 4.022 & 2.25 \\
\hline h3 & 31.25 & 12.50 & 230 & 4.022 & 2.50 \\
\hline h4 & 34.38 & 12.50 & 230 & 4.022 \\
\hline h5 & 37.50 & 12.50 & 230 & 2.75 \\
\hline
\end{tabular}

The reinforcement reductions (As) are between $10.00 \%$ and $50.00 \%$ of the initial value given in the reference model.

Table 5. Proposed variation for the reinforcement area $\left(A_{s}\right)$.

\begin{tabular}{cccccc}
\hline Test & $\mathbf{h}(\mathbf{c m})$ & $\mathbf{b}(\mathbf{c m})$ & $\mathbf{L}(\mathbf{c m})$ & As $\left(\mathbf{c m}^{\mathbf{2}}\right)$ & Reinforced area reduction $(\mathbf{\%})$ \\
\hline as0 & 25.00 & 12.50 & 230.00 & 4.02 & - \\
\hline as1 & 25.00 & 12.50 & 230.00 & 3.62 & $10 \%$ \\
\hline as2 & 25.00 & 12.50 & 230.00 & 3.22 & $20 \%$ \\
\hline as3 & 25.00 & 12.50 & 230.00 & 2.82 & $30 \%$ \\
as4 & 25.00 & 12.50 & 230.00 & 2.41 & $40 \%$ \\
\hline as5 & 25.00 & 12.50 & 230.00 & 2.01 & $50 \%$ \\
\hline
\end{tabular}

Test 3 is performed changing the free span (L) of the beam. As mentioned in and Pereira and Pituba [51], it is important to note that in this simulation the distance between the bending loads at 4 points was always maintained in a range close to $L / 3$ ensuring that the test always has the same pattern as the previous ones. This procedure allows the comparison of load versus displacement to be done properly. The reinforcement area is kept constant at $A s=4.022 \mathrm{~cm}^{2}$.

Table 6. Span variation proposal $(L)$.

\begin{tabular}{cccccccc}
\hline Test & $\boldsymbol{h}(\mathbf{c m})$ & $\boldsymbol{b w}(\mathbf{c m})$ & $\boldsymbol{L}(\mathbf{c m})$ & $\boldsymbol{A s}\left(\mathbf{c m}^{\mathbf{2}}\right)$ & $\begin{array}{c}\text { Reinforcement area } \\
\text { reduction } \mathbf{( \% )}\end{array}$ & $\begin{array}{c}\text { 1st load } \\
\text { position } \\
(\mathbf{c m})\end{array}$ & $\begin{array}{c}\text { Distance } \\
\text { between loads } \\
(\mathbf{c m})\end{array}$ \\
\hline L0 & 25.00 & 12.50 & 230.00 & 200.00 & 4.022 & 80.00 & 70.00 \\
\hline L1 & 26.25 & 12.50 & 280.00 & 250.00 & 4.022 & 97.50 & 85.00 \\
\hline L2 & 25.13 & 12.50 & 330.00 & 300.00 & 4.022 & 115.00 & 100.00 \\
\hline L3 & 31.25 & 12.50 & 380.00 & 350.00 & 4.022 & 130.00 & 120.00 \\
\hline L4 & 34.38 & 12.50 & 430.00 & 400.00 & 4.022 & 147.50 & 135.00 \\
\hline L5 & 37.50 & 12.50 & 480.00 & 450.00 & 4.022 & 165.00 & 150.00 \\
\hline
\end{tabular}

The analyses are based on the verification of load versus displacement curves of the numerical models generated by the finite element code. two volumetric fibers concentrations of $2.00 \%$ and $2.50 \%$ are used. Note that the numerical analyses are performed using displacement control taking the node localized in the middle span as reference. Therefore, the load versus displacement graphs presented in this work characterize the loading $\mathrm{P}+\mathrm{P}$ (represented in Figure 3 ) and the displacement in the middle of the beam span.

\section{RESULTS AND DISCUSSIONS}

In this section, the results of numerical simulations are presented. These results intend to compare the simulations for $2.00 \%$ and $2.50 \%$ of fiber volume. The results will be presented in the following sequence: $(i)$ height variation $(h)$; 
(ii) reinforcement area variation $(A s)$; and (iii) span length variation $(L)$. Note that in Figures 5, 6 and 7, the curves on the left axis referring to tests with $2.50 \%$ of fiber volume and on the right axis the curves referring to tests with $2.00 \%$ of fiber volume.

The first simulation compares the obtained results for the beam with volumes of steel fibers of $2.00 \%$ and $2.50 \%$ considering height variation $(h)$ of the beams. The results are presented in Figure 5.

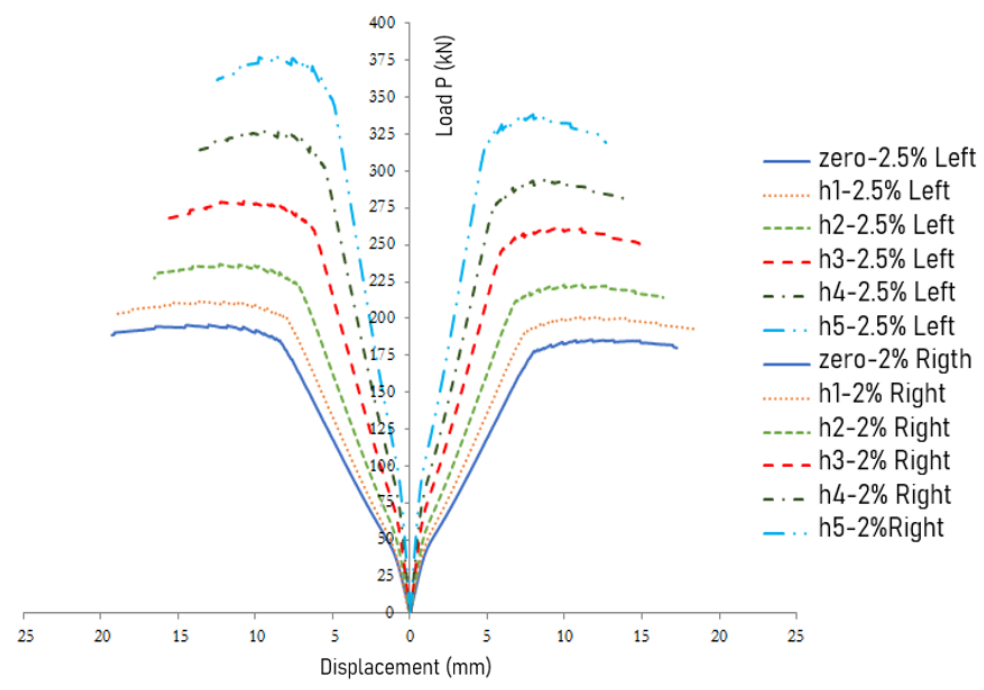

Figure 5. Load-displacement in the middle of the span for height variation (Table 4).

Observe that the gains in strength and stiffness have been evidenced for height increases in both situations (for $2.00 \%$ and $2.50 \%$ of fiber volume). It is possible to note that the height increasing leads to a gain of mechanical strength since from the region of the Serviceability Limit State (SLR) to the collapse regime of the beam. For a concentration of $2.00 \%$ of fibers, the increase in the ultimate load of the structure for the case h5 is up to $81.56 \%$ when compared to the $\mathrm{h} 0$ case (the reference model). For $2.50 \%$ of fiber volume, the increase is up to $93.31 \%$. For details, Table 7 presents the total gain in each performed test. Besides, it is possible to note that when $\mathrm{h} 4$ and $\mathrm{h} 5$ tests are compared, the gains are about $7.00 \%$ and $12.00 \%$ for $2.00 \%$ and $2.50 \%$ of fiber volume cases, respectively.

Table 7. Maximum loads and loads in the SLS for tests with height variation $(h)$.

\begin{tabular}{ccccc}
\hline Test & Maximum load (kN) & SLS Load (kN) & $\begin{array}{c}\text { Increasing of SLS load } \\
(\mathbf{k N})\end{array}$ & $\begin{array}{c}\text { Increasing of SLS load } \\
(\%)\end{array}$ \\
\hline h0-2.0\% & 186.17 & 74.46 & --- & --- \\
\hline h1-2.0\% & 200.42 & 80.16 & 14.25 & $7.66 \%$ \\
\hline h2-2.0\% & 223.02 & 89.20 & 36.85 & $19.79 \%$ \\
\hline h3-2.0\% & 262.35 & 104.94 & 76.18 & $40.92 \%$ \\
\hline h4-2.0\% & 294.47 & 117.79 & 108.30 & $58.18 \%$ \\
\hline h5-2.0\% & 338.00 & 135.20 & 151.83 & $81.56 \%$ \\
\hline h0-2.5\% & 195.38 & 78.15 & ---- & - \\
\hline h1-2.5\% & 211.38 & 84.55 & 15.99 & $8.19 \%$ \\
\hline h2-2.5\% & 236.59 & 94.63 & 41.21 & $21.10 \%$ \\
\hline h3-2.5\% & 280.67 & 112.26 & 85.29 & $43.65 \%$ \\
\hline h4-2.5\% & 327.76 & 131.10 & 132.38 & $67.76 \%$ \\
\hline h5-2.5\% & 377.69 & 151.07 & 182.31 & $93.31 \%$ \\
\hline
\end{tabular}


In order to capture the contribution of steel fibers to the ultimate load of the analysed beams, Table 7 compares the situations $\mathrm{h} 0-2.0 \%$ and $\mathrm{h} 0-2.5 \%$. For these situations it is possible to note that only the change in fiber volume represents an increasing of $9.21 \mathrm{kN}$ on the ultimate load. Regarding $\mathrm{h} 5-2.0 \%$ and $\mathrm{h} 5-2.5 \%$, there is an increase of $39.69 \mathrm{kN}$. If the two strength gains previously mentioned are compared, there is a total of $30.48 \mathrm{kN}$ for an increasing in section height from $25 \mathrm{~cm}$ (case h0) to $37.50 \mathrm{~cm}$ (case h5). It can be concluded that the increasing in fiber volume leads to a higher strength gain for high values for $\mathrm{h} / \mathrm{b}$ ratio.

Table 8 presents the comparison of the load according to specific displacement measurement points in order to evaluate the load versus displacement behaviour. For theses analyses, it has been investigated the states of the beams for $4 \mathrm{~mm}, 8 \mathrm{~mm}$ and $12 \mathrm{~mm}$ displacement cases.

Table 8. Comparative study about load versus displacement for 4, 8 and $12 \mathrm{~mm}$ for all simulations with height variation $(h)$.

\begin{tabular}{cccc}
\hline Test & Load at 4 $\mathbf{~ m m}(\mathbf{k N})$ & Load at 8 $\mathbf{~ m m}(\mathbf{k N})$ & Load at 12 $\mathbf{~ m m}(\mathbf{k N})$ \\
\hline $\mathrm{h} 0-2.0 \%$ & 99.50 & 178.42 & 185.24 \\
$\mathrm{~h} 1-2.0 \%$ & 112.76 & 193.42 & 199.72 \\
\hline $\mathrm{h} 2-2.0 \%$ & 134.86 & 217.36 & 221.62 \\
\hline $\mathrm{h} 3-2.0 \%$ & 177.09 & 258.02 & 258.18 \\
\hline $\mathrm{h} 4-2.0 \%$ & 214.35 & 290.77 & 285.80 \\
\hline $\mathrm{h} 5-2.0 \%$ & 269.41 & 334.93 & 324.97 \\
\hline $\mathrm{h} 0-2.5 \%$ & 97.68 & 177.79 & 193.73 \\
\hline $\mathrm{h} 1-2.5 \%$ & 111.30 & 199.52 & 211.06 \\
\hline $\mathrm{h} 2-2.5 \%$ & 133.98 & 226.77 & 235.82 \\
\hline $\mathrm{h} 3-2.5 \%$ & 177.59 & 274.22 & 279.33 \\
\hline $\mathrm{h} 4-2.5 \%$ & 228.45 & 324.22 & 321.53 \\
\hline $\mathrm{h} 5-2.5 \%$ & 288.17 & 374.58 & 363.91 \\
\hline
\end{tabular}

Looking at Table 8, it is possible to state that for the cases of $\mathrm{h} 0-2.0 \%$ and $\mathrm{h} 0-2.5 \%$, in a displacement of $12 \mathrm{~mm}$, the higher fiber volume implies an increasing in the corresponding load of $8.49 \mathrm{kN}(185.24 \mathrm{kN}$ to $193.73 \mathrm{kN})$ equivalent to an increasing of $4.58 \%$. This gain is more evident in the comparison of cases $\mathrm{h} 5-2.0 \%$ and h5-2.5\% in the displacement of $12 \mathrm{~mm}$, with 38.94 $\mathrm{kN}$ (an increase of 11.98\%). Therefore, it can be concluded that in situations with more damaged states, the greater will be the contribution of the reinforcement and steel fiber set to the stiffness of the structural element.

The second simulation compares the obtained results for beams with fiber volumes of $2.00 \%$ and $2.50 \%$ considering a reinforcement variation. As previously mentioned, this simulation shows reductions in the original reinforcement. Figure 6 presents the results for such simulation.

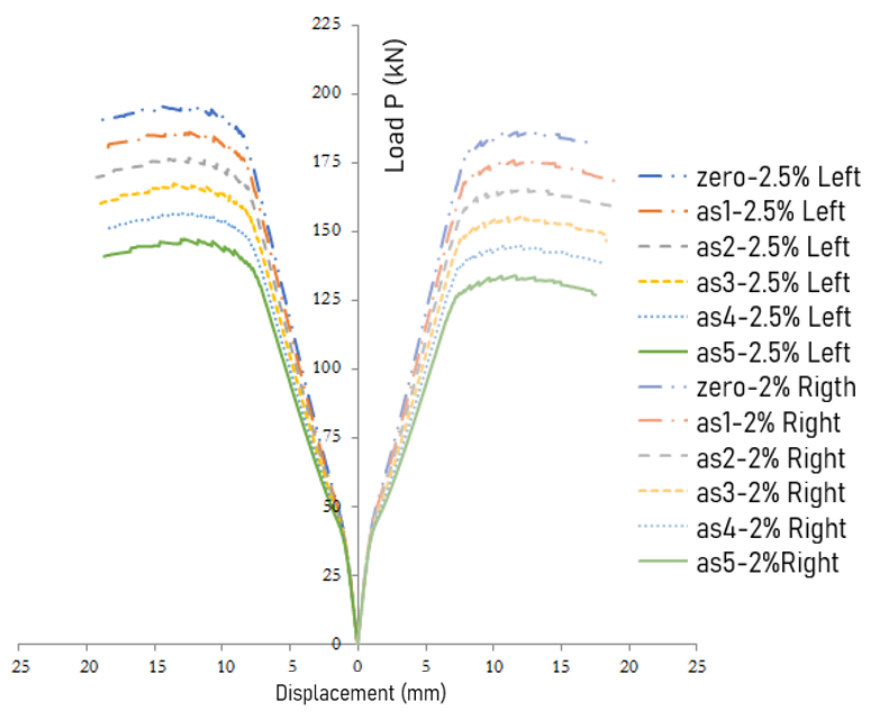

Figure 6. Load-displacement in the middle of the span to reinforcement area variation(Table 5). 
As expected, as the total area of the longitudinal reinforcement is reduced, the peak load of the structural element is reduced. However, it is worth mentioning that between the as 0 and the as 5 tests with $50.00 \%$ decreasing in the reinforcement, it is observed that in none of the scenarios there was a load reduction more than $28.00 \%$ within the analyses for the same fiber volume showing the effective role of steel fibers on the structural element. Besides, it is observed a reduction in the load of $4.66 \mathrm{kN}$ (load in the SLS) regarding to the test as $4-2.50 \%$ for the test as $4-2.00 \%$. For more details, Table 9 presents each test performed and comparative analyses of the variations of the steel fibers concentrations.

Table 9. Maximum loads and loads in the SLS for the tests with reinforcement area variation (As).

\begin{tabular}{ccccc}
\hline Test & Maximum load (kN) & SLS load (kN) & Decreased load on SLS (kN) & $\begin{array}{c}\text { Decreased load on } \\
\text { SLS (\%) }\end{array}$ \\
\hline as0-2.0\% & 186.17 & 74.46 & ---- & --- \\
\hline as1-2.0\% & 176.34 & 70.53 & 3.93 & $5.28 \%$ \\
\hline as2-2.0\% & 165.71 & 66.28 & 8.18 & $10.99 \%$ \\
\hline as3-2.0\% & 155.75 & 62.30 & 12.16 & $16.34 \%$ \\
\hline as $4-2.0 \%$ & 144.96 & 57.98 & 16.48 & $22.14 \%$ \\
\hline as5-2.0\% & 134.21 & 53.68 & 20.78 & $27.91 \%$ \\
\hline as $0-2.5 \%$ & 195.38 & 78.15 & ---- & --- \\
\hline as $1-2.5 \%$ & 185.89 & 74.35 & 3.79 & $4.86 \%$ \\
\hline as2-2.5\% & 176.47 & 70.58 & 11.30 & $9.68 \%$ \\
\hline as3-2.5\% & 167.13 & 66.85 & 15.50 & $14.46 \%$ \\
\hline as $4-2.5 \%$ & 156.62 & 62.64 & 19.27 & $19.84 \%$ \\
\hline as5-2.5\% & 147.19 & 58.87 & $24.66 \%$ \\
\hline
\end{tabular}

Table 10 presents a comparative study of loads according to points of displacement measurements. For theses analyses, it has been investigated the states of the beams for $4 \mathrm{~mm}, 8 \mathrm{~mm}$ and $12 \mathrm{~mm}$ displacement cases.

Table 10. Comparative study about load versus displacement for 4,8 and $12 \mathrm{~mm}$ for all simulations with reinforcement area variation $(A s)$.

\begin{tabular}{cccc}
\hline Test & Load at 4 mm $\mathbf{~ k N})$ & Load at 8 $\mathbf{~ m m}(\mathbf{k N})$ & Load at 12 mm $(\mathbf{k N})$ \\
\hline as0-2.0\% & 99.50 & 178.43 & 185.24 \\
\hline as1-2.0\% & 95.60 & 168.76 & 175.06 \\
as2-2.0\% & 91.65 & 158.40 & 165.16 \\
\hline as3-2.0\% & 87.61 & 148.68 & 155.35 \\
as4-2.0\% & 83.31 & 139.58 & 144.67 \\
\hline as5-2.0\% & 78.91 & 129.15 & 132.97 \\
\hline as0-2.5\% & 97.68 & 177.79 & 193.73 \\
\hline as1-2.5\% & 94.28 & 170.35 & 184.85 \\
\hline as2-2.5\% & 90.80 & 163.88 & 175.36 \\
\hline as3-2.5\% & 87.28 & 156.24 & 166.13 \\
\hline as4-2.5\% & 83.44 & 146.81 & 155.95 \\
\hline as5-2.5\% & 79.60 & 137.37 & 145.77 \\
\hline
\end{tabular}

As previously mentioned, it is possible to observe that the steel fibers have influenced the nonlinear behaviour of the structural element not allowing that a reduction in the reinforcement rate would lead to a massive impact on the ultimate load value. It can be seen that in the $8 \mathrm{~mm}$ displacement situation, in cases of loading with as $5-2.50 \%$ to as5$2.00 \%$ there was a total reduction in the maximum load value of $8.22 \mathrm{kN}(137.37 \mathrm{kN}$ to $129.15 \mathrm{kN})$, i. e., just a reduction of 5.98\%. Obviously, the focus in this work is the use of simplified models to practical applicability [27], but to study the non-linear aspect of the performed analyses in more details, two and three-dimensional analyses with more complex damage models have to be applied in order to better understand the dissipative phenomena involved.

The third simulation compares the results obtained for the beam with steel fiber volumes of $2.00 \%$ and $2.50 \%$ considering a span variation. Each simulation has an increasing of $50 \mathrm{~cm}$ in the effective span as shown in Table 6 . Figure 7 presents the results for such simulation. 


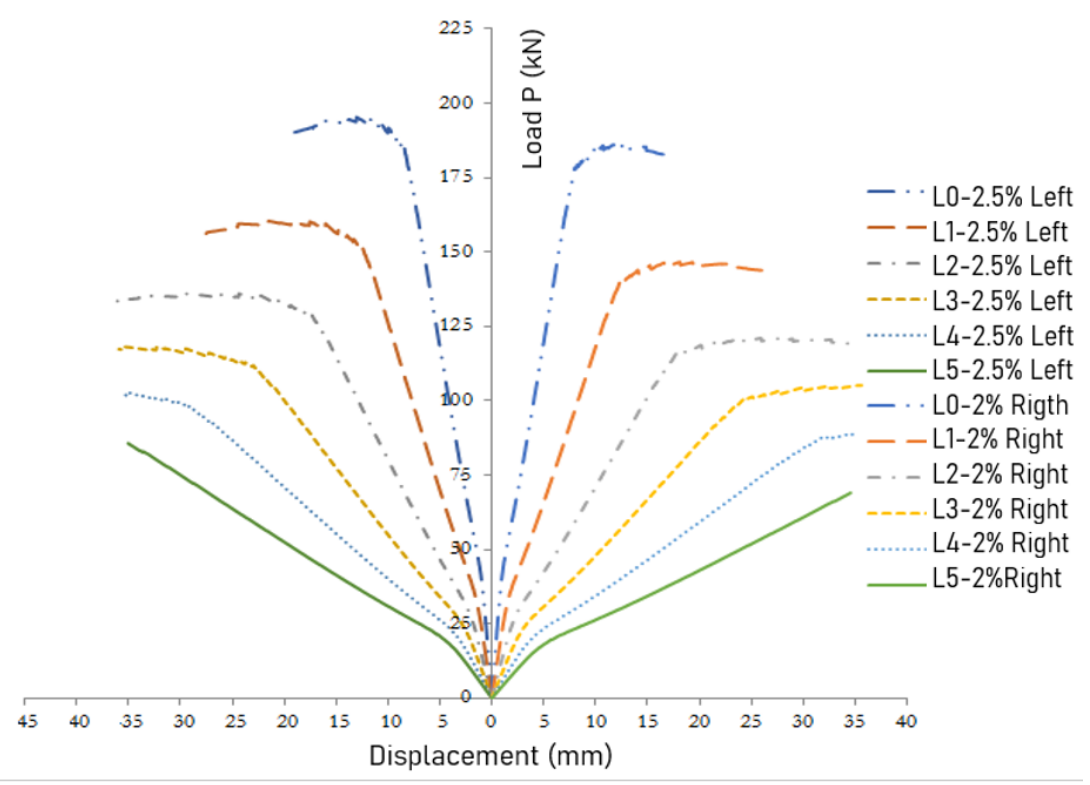

Figure 7. Load-displacement in the middle of the span to span length variation (Table 6).

For the L5 standard test, there is an increasing of approximately $24.00 \%$ in the peak load comparing L5-2.00\% to L5-2.50\%. Table 11 presents all tests.

Table 11. Maximum loads and loads in the SLS for tests with span length variation $(L)$.

\begin{tabular}{|c|c|c|c|c|}
\hline Test & Maximum load (kN) & SLS load $(k N)$ & Decreased load on SLS (kN) & Decreased load on SLS (\%) \\
\hline L0-2.0\% & 186.17 & 74.47 & $\begin{array}{c}--- \\
--\end{array}$ & $\begin{array}{c}--- \\
-\cdots\end{array}$ \\
\hline $\mathrm{L} 1-2.0 \%$ & 146.66 & 58.66 & 15.81 & $21.23 \%$ \\
\hline $\mathrm{L} 2-2.0 \%$ & 121.03 & 48.41 & 26.06 & $34.99 \%$ \\
\hline $\mathrm{L} 3-2.0 \%$ & 105.20 & 42.08 & 32.39 & $43.49 \%$ \\
\hline L $4-2.0 \%$ & 88.84 & 35.54 & 38.93 & $52.28 \%$ \\
\hline L5-2.0\% & 69.01 & 27.61 & 46.86 & $62.93 \%$ \\
\hline $\mathrm{L} 0-2.5 \%$ & 195.38 & 78.15 & ---- & ---- \\
\hline $\mathrm{L} 1-2.5 \%$ & 160.51 & 64.20 & 13.95 & $17.85 \%$ \\
\hline $\mathrm{L} 2-2.5 \%$ & 136.17 & 54.47 & 23.68 & $30.30 \%$ \\
\hline L3-2.5\% & 118.27 & 47.31 & 30.85 & $39.47 \%$ \\
\hline L4- $2.5 \%$ & 102.66 & 41.06 & 37.09 & $47.46 \%$ \\
\hline $\mathrm{L} 5-2.5 \%$ & 85.71 & 34.28 & 43.87 & $56.13 \%$ \\
\hline
\end{tabular}

It is possible to verify that the simulations $\mathrm{L} 1-2.00 \%$ and $\mathrm{L} 1-2.50 \%$ have a difference of $13.85 \mathrm{kN}$ representing a reduction of $8.63 \%$ in the load value $(160.51 \mathrm{kN}$ to $146.66 \mathrm{kN})$. For the $\mathrm{L} 5-2.00 \%$ and L5-2.50\% simulations, this difference reached $19.48 \%$. When the results of span reduction $(L)$ are compared with the results of reinforcement reduction $(A s)$, it is noted that the span reduction $(L)$ is always preponderant concerning to the reinforcement area $(A s)$ because in the simulations L5 the reductions reach values higher than $56.00 \%$ while the reduction of the reinforcement provides a decreasing in load in the SLS lower than $28.00 \%$.

Table 12 shows the comparative study of the load decreasing as a function of displacement measurement points. For theses analyses, it has been investigated the states of the beams for $4 \mathrm{~mm}, 8 \mathrm{~mm}$ and $12 \mathrm{~mm}$ displacement cases.

In Table 12, it is possible to notice that the load reductions are approximately $39.44 \mathrm{kN}$ for a displacement of $4 \mathrm{~mm}$ regarding to reference test 1 (2.0\% of fiber volume) when compared to reference test 0 ( $2.0 \%$ of fiber volume). For the same tests with $2.5 \%$ of fiber volume, the reduction is about $38.33 \mathrm{kN}$. Table 13 shows the load reductions compared to the reference zero model. 
Table 12. Comparative study about load versus displacement for 4,8 and $12 \mathrm{~mm}$ for all simulations with variation of the effective span length (L).

\begin{tabular}{|c|c|c|c|}
\hline Test & Load at $4 \mathrm{~mm}(\mathrm{kN})$ & Load at $8 \mathrm{~mm}(\mathrm{kN})$ & Load at $12 \mathrm{~mm}(\mathrm{kN})$ \\
\hline L0-2.0\% & 95.50 & 178.43 & 185.24 \\
\hline L1-2.0\% & 56.06 & 97.02 & 136.98 \\
\hline $\mathrm{L} 2-2.0 \%$ & 37.27 & 59.32 & 83.2 \\
\hline L3-2.0\% & 27.52 & 40.8 & 55.36 \\
\hline L4-2.0\% & 20.57 & 30.03 & 39.18 \\
\hline L5-2.0\% & 15.35 & 23.32 & 29.5 \\
\hline $\mathrm{L} 0-2.5 \%$ & 97.68 & 177.79 & 193.73 \\
\hline L1-2.5\% & 59.35 & 103.65 & 147.09 \\
\hline L $2-2.5 \%$ & 40.74 & 66.47 & 94.02 \\
\hline L3-2.5\% & 30.18 & 46.29 & 63.98 \\
\hline L4-2.5\% & 23.28 & 34.50 & 46.16 \\
\hline $\mathrm{L} 5-2.5 \%$ & 17.95 & 27.09 & 34.99 \\
\hline
\end{tabular}

Table 13 Comparison study about load reduction with displacements of 4, 8 and $12 \mathrm{~mm}$.

\begin{tabular}{ccccccc}
\hline Test & $\begin{array}{c}\text { Load at 4 mm } \\
(\mathbf{k N})\end{array}$ & $\begin{array}{c}\text { Load reduction } \\
(\mathbf{k N})\end{array}$ & $\begin{array}{c}\text { Load at 8 } \mathbf{~ m m} \\
(\mathbf{k N})\end{array}$ & $\begin{array}{c}\text { Load reduction } \\
(\mathbf{k N})\end{array}$ & $\begin{array}{c}\text { Load at 12 } \\
\mathbf{m m}(\mathbf{k N})\end{array}$ & $\begin{array}{c}\text { Load reduction } \\
(\mathbf{k N})\end{array}$ \\
\hline L0-2.0\% & 95.50 & --- & 178.43 & --- & 185.24 & -- \\
\hline L1-2.0\% & 56.06 & 39.44 & 97.02 & 81.41 & 136.98 & 48.26 \\
\hline L2-2.0\% & 37.27 & 58.23 & 59.32 & 119.10 & 83.20 & 102.00 \\
\hline L3-2.0\% & 27.52 & 67.98 & 40.80 & 137.63 & 55.36 & 129.88 \\
\hline L4-2.0\% & 20.57 & 74.93 & 30.03 & 148.40 & 39.18 & 146.06 \\
\hline L5-2.0\% & 15.35 & 80.15 & 23.32 & 155.11 & 29.50 & 155.74 \\
\hline L0-2.5\% & 97.68 & -- & 177.70 & -- & 193.70 & -- \\
\hline L1-2.5\% & 59.35 & 38.33 & 103.65 & 74.14 & 147.09 & 46.64 \\
\hline L2-2.5\% & 40.74 & 56.94 & 66.47 & 111.30 & 94.02 & 99.71 \\
\hline L3-2.5\% & 30.18 & 67.50 & 46.29 & 131.50 & 63.98 & 129.70 \\
\hline L4-2.5\% & 23.28 & 74.40 & 34.50 & 143.29 & 46.16 & 147.57 \\
\hline L5-2.5\% & 17.95 & 79.73 & 27.09 & 150.70 & 34.99 & 158.74 \\
\hline
\end{tabular}

It is possible to verify that the loading decreased considerably at $4 \mathrm{~mm}, 8 \mathrm{~mm}$ and $12 \mathrm{~mm}$, showing the loss of the strength when the span length is increased. When analysing the displacement points and their respective forces, it is noticed that for $4.00 \mathrm{~mm}$ of displacement the load reduces from $35 \mathrm{kN}$ to $80 \mathrm{kN}$ approximately in both fiber volumes. For displacements of $8 \mathrm{~mm}$ and $12 \mathrm{~mm}$, this value ranges from approximately $46 \mathrm{kN}$ to $158 \mathrm{kN}$.

Another important issue to be evaluate is the non-linear aspect of the load versus displacement behaviour which, in the case of span reduction, implied in a sharp drop in bending stiffness of the structural element when compared with the reinforcement area variation showed in Figure 6, for example.

\section{CONCLUSIONS}

In the context of studies performed in this work, it was evidenced that the steel fibers have a great potential to improve the mechanical properties of the concrete, which can promote gains in the ductility of the structural elements. This information is also found by experimental analyses presented in [21]-[23], [50], [52]-[54]. The regions of beams which behave in State II (section with cracks, the contribution of the concrete submitted to tension stress is not considered for the equilibrium of the transversal section) evidence the improving of stiffness when the results are compared between models with the same characteristics and different concentrations of fiber volume (2.00\% and $2.5 \%)$ in Figures 5,6 and 7, despite the predominant influence in strength gain when analyzing the increase in the height of the cross section (Figure 5).

The results obtained in this work confirm that height and span length are perhaps the most influential properties on the deformability process of damaged structural elements. This influence is evidenced quantitatively in the present work by simulations which pointed out that when increasing the height of the cross section increases more than $90.00 \%$ in the ultimate load are observed. On the other hand, for the span length, the change is sensitive in the sense of reducing 
the ultimate load. For example, for beams with $2.00 \%$ of fiber concentration, the reduction obtained was between approximately $21.00 \%$ to $63.00 \%$. For simulations involving beams with a concentration of $2.50 \%$, the ultimate load reduction also occurred, and it was in the range of $17.00 \%$ to $56.00 \%$.

Regarding the tests dealing with variation of the longitudinal reinforcement, reductions between $10.00 \%$ and $50.00 \%$ of the bending reinforcement have been performed (both for $2.00 \%$ and $2.50 \%$ of fiber concentration). However, in none of the cases, a reduction higher than $25.00 \%$ of the ultimate load has occurred. This fact is possibly attributed, in part, to the strength promoted by the griping effect of steel fibers. It is also observed that the presence of fibers in the cementitious matrix reduces the level of displacement on the structural elements, even if there is a significant reduction in the reinforcement area. Therefore, it is observed that the present work contributes to visualize an estimative of percentages of reduction and/or increasing of the displacements and internal efforts caused by the geometric parameter variations of the SFRC beams analyzed so far.

Another important issue to be observed in this work is that the addition of a volume of steel fibers in the structural system have allowed a reduction in the reinforcement without significant loss of flexural stiffness (Figure 6) in the service loading situations. In the context of structural design, this situation is interesting since the opening cracks and displacements of the structural elements are related to this flexural stiffness. Thus, it is possible to state that the use of fibers will allow a reduction in the reinforcement density without detriment to the bending strength properties, mainly in parts with high $h / b_{w}$ ratio. Another issue is the improvement in the effectiveness of using fibers in structural elements with larger span lengths, where the cracking process is more intense, and the number of cracks is high.

More experimental and numerical tests must be performed to obtain answers with the possibility of statistical treatment and contribute to obtaining a methodology for estimating displacements in SFRC beams. It is also worth mentioning the importance of numerical analyses, as experimental analyses have high costs involved, unlike numerical analyses that allow different structural elements to be analyzed without higher costs. Therefore, this work contributes to the understanding and dissemination of the use of SRFC in Brazil.

\section{ACKNOWLEDGEMENTS}

The authors wish to thank to CNPq (National Council for Scientific and Technological Development) and FAPEG (Goias Research Foundation).

\section{REFERENCES}

[1] A. Medeiros, "Estudo do comportamento à fadiga em compressão do concreto com fibras," Ph.D. dissertation, Pontif. Univ. Catol. Rio de Janeiro, 2012.

[2] S. Khan, S. Islam, and Z. Rizvi, "Innovation in steel fibre reinforced concrete - a review," Int. J. Res. Eng. Appl. Sci., vol. 3, pp. 21$33,2014$.

[3] W. M. Pereira Jr., J. J. C. Pituba, and D. L. Araújo, "Numerical analysis of steel fiber rein-forced concrete beams using damage mechanics," IBRACON Struct. Mater. J., vol. 9, no. 2, pp. 153-191, 2016, http://dx.doi.org/10.1590/S1983-41952016000200002.

[4] R. P. Salvador, J. F. Fernandes, and A. D. Figueiredo, "Assessment of concrete reinforced with low content of fibres for structural purposes according to standard EN 14651-2007," Rev. Materia, vol. 20, pp. 961-974, 2015, http://dx.doi.org/10.1590/S1517707620150004.0100

[5] Associação Brasileira de Normas Técnicas, Fibras de Aço para Concretos - Especificação - Procedimento, NBR 15530, 2007.

[6] Associação Brasileira de Normas Técnicas, Tubo de Concreto Armado de Seção Circular para Esgoto Sanitário, NBR 8890, 2007.

[7] J. Katzer, "Steel fibers and steel fiber reinforced concrete in civil engineering," Pac. J. Sci. Technol., vol. 7, no. 1, pp. 53-58, 2006.

[8] A. M. Brandt, "Fibre reinforced cement-based (FRC) composites after over 40 years of development in building and civil engineering," Compos. Struct., vol. 86, no. 1-3, pp. 3-9, 2008, http://dx.doi.org/10.1016/j.compstruct.2008.03.006.

[9] A. N. Ali and M. V. Mohod, "A review on effect of fiber reinforced concrete on rigid pavement," Int. J. Res. Eng. Sci. Technol., vol. 1, pp. 222-227, 2015.

[10] V. Gribniak, V. Tamulenas, P.-L. Ng, A. K. Arnautov, E. Gudonis, and I. Misiunaite, "Mechanical behavior of steel fiber-reinforced concrete beams bonded with external carbon fiber sheets," Pac. J. Sci. Technol., vol. 10, no. 6, pp. 1-18, 2017.

[11] E. A. Latifa, R. Aguswari, and P. H. Wardoyo, "Performance of steel fiber concrete as rigid pavement," Adv. Mat. Res., vol. 723, pp. 452-458, 2013, http://dx.doi.org/10.4028/www.scientific.net/AMR.723.452.

[12] American Concrete Institute, State-of-the-Art Report on Fiber Reinforced Concrete, ACI 544.1R-96, 2006.

[13] American Concrete Institute, Measurement of Properties of Fiber Reinforced Concrete - Manual of Concrete Practice, ACI 544.2R89, 2006 
[14] American Concrete Institute, Guide for Specifying, Proportioning, Mixing, Placing and Finishing Steel Fiber Reinforced Concrete, ACI 544.3R-93, 2006.

[15] American Concrete Institute, Design Considerations for Steel Fiber Reinforced Concrete, ACI 544.4R-88, 2006.

[16] American Concrete Institute, Building Code Requirements for Structural Concrete, ACI 318, 2006.

[17] International Union of Laboratories and Experts in Construction Materials, Systems and Structures, "RILEM TC 162-TDF - test and design methods for steel fiber reinforced concrete: bending test - final recommendation," Mater. Struct., vol. 35, no. 253, pp. 579$582,2002$.

[18] International Federation for Structural Concrete, Model Code for Concrete Structures 2010, 2013.

[19] European Committee for Standardization, Test Method for Metallic Fibered Concrete - Measuring the Flexural Tensile Strength (Limit of Proportionality (LOP), Residual, EN 14651, 2005.

[20] N. Banthia and J. F. Trottier, "Test methods for flexural toughness characterization of fiber rein-forced concrete: some concerns and a proposition," ACI Mater. J., vol. 92, no. 2, pp. 48-57, 1995.

[21] T. E. T. Buttignol, J. L. A. O. Sousa, and T. N. Bittencourt, "Ultra high-performance fiber-reinforced concrete (UHPFRC): a review of material properties and design," IBRACON Struct. Mater. J., vol. 10, no. 4, pp. 957-971, 2017.

[22] T. Błaszczyński and M. P. Falek, "Steel fiber reinforced concrete as a structural material," Procedia Eng., vol. 122, pp. 282-289, 2015.

[23] D.-Y. Yoo, N. Banthia, and Y. S. Yoon, "Experimental and numerical study on flexural behavior of ultra-high-performance fiber reinforced concrete beams with low reinforcement ratios," Can. J. Civ. Eng., vol. 44, no. 1, pp. 18-28, 2017.

[24] J. J. C. Pituba, “Sobre a formulação de um modelo de dano para concreto,” Ph.D. dissertation, Esc. Eng. São Carlos, Univ. São Paulo, São Carlos, 2003.

[25] J. J. C. Pituba, "Validação de um modelo de dano para a análise não-linear de estruturas em concreto armado," Acta Scientiarum, vol. 32 , no. 3, pp. 251-259, 2010.

[26] J. J. C. Pituba and G. R. Fernandes, "An anisotropic damage model for concrete," J. Eng. Mech., vol. 137, no. 9, pp. 610-624, 2011.

[27] M. M. S. Lacerda and J. J. C. Pituba, "Simplified damage models applied in the numerical analysis of reinforced concrete structures," IBRACON Struct. Mater. J., vol. 5, pp. 26-37, 2012.

[28] L. A. F. Souza and R. D. Machado, "Numerical-computational analysis of reinforced concrete structures considering the damage, fracture and failure criterion," IBRACON Struct. Mater. J., vol. 6, no. 1, pp. 101-120, 2013.

[29] J. J. C. Pituba and R. G. Delalibera, "Evaluation of deflection in reinforced concrete structures using damage mechanics," IBRACON Struct. Mater. J., vol. 7, pp. 68-99, 2014.

[30] J. J. C. Pituba and W. M. Pereira Jr., "A bi-dissipative damage model for concrete," IBRACON Struct. Mater. J., vol. 8, no. 1, pp. 49$65,2015$.

[31] C. G. Nogueira, "Modelo mecânico para estruturas lineares em concreto armado - uma abordagem acoplada entre a mecânica do dano e algoritmos de otimização," Eng. Estudo Pesqui., vol. 12, no. 2, pp. 14-27, 2012.

[32] G. M. S. Alva, A. L. H. C. El Debs, and J. Kaminski Jr., "Nonlinear analysis of reinforced concrete structures in design procedures: application of lumped dissipation models," IBRACON Struct. Mater. J., vol. 3, pp. 149-178, 2010.

[33] A. Cipollina, A. López-Inojosa, and J. Flórez-López, "A simplified damage mechanics approach to nonlinear analysis of frames," Comput. Struc., vol. 54, no. 6, pp. 1113-1126, 1995, http://dx.doi.org/10.1016/0045-7949(94)00394-I.

[34] M. G. Santoro and S. K. Kunnath, "Damage-based RC beam element for nonlinear structural analysis," Eng. Struct., vol. 49, pp. 733$742,1995$.

[35] J. Flórez-Lópes, "Simplified model of unilateral damage for RC frames," J. Struct. Eng., vol. 121, no. 12, pp. 1765-1772, 1995.

[36] K. O. Coelho and E. D. Leonel, "Modelo de dano concentrado aplicado à modelagem mecânica de estruturas em concreto armado," in XXXVII Iber. Lat. Am. Congr. Comput. Methods Eng., Brasília, 2016.

[37] R. C. G. Menin, L. M. Trautwein, and T. N. Bittencourt, "Smeared crack models for reinforced concrete beams by finite element methods," IBRACON Struct. Mater. J., vol. 2, no. 2, pp. 166-200, 2009.

[38] S. S. Penna, R. L. S. Pitangueira, and J. S. Fuina, "Estudo Comparativo de modelos de fissuração distribuída para estruturas de concreto," Semin. Ciênc. Exatas Tecnol., vol. 34, no. 2, pp. 211-228, 2013.

[39] T. M. Pacheco, J. M. F. Lima, and P. Lima, "R L. Influence of cracking models on numerical analysis of reinforced concrete beam," Sci. Eng. J., vol. 22, pp. 57-63, 2013.

[40] D. S. Oliveira, R. Barros, and J. S. Giongo, "Six pile caps reinforced concrete: numerical simulation and design by the strut and tie method," IBRACON Struct. Mater. J., vol. 7, pp. 1-23, 2014.

[41] D. C. Borges, W. M. G. Quaresma, G. R. Fernandes, and J. J. C. Pituba, "Evaluation of a proposed model for concrete at mesoscopic scale," IBRACON Struct. Mater. J., vol. 10, no. 5, pp. 1087-1112, 2017. 
[42] T. E. T. Buttignol and L. C. Almeida, "Three-dimensional analysis of two-pile caps," IBRACON Struct. Mater. J., vol. 5, no. 2, pp. 252-283, 2012.

[43] A. Carpinteri and M. Corrado, "Nonlinear Fracture Mechanics investigation on the ductility of reinforced concrete beams," IBRACON Struct. Mater. J., vol. 3, no. 2, pp. 137-148, 2010.

[44] X. Ren and J. Li, "Multi-scale based fracture and damage analysis of steel fiber reinforced concrete," Eng. Fail. Anal. China, vol. 35, pp. 253-261, 2013.

[45] V. F. P. Dutra, S. Maghous, and A. Campos Fo., "A homogenization approach to macroscopic strength criterion of steel fiber reinforced concrete," Cement Concr. Res., vol. 44, pp. 34-45, 2013.

[46] J. Oliver, D. F. Mora, A. E. Huespe, and R. Weyler, "A micromorphic model for steel fiber reinforced concrete," Int. J. Solids Struct., vol. 49, no. 21, pp. 2990-3007, 2012.

[47] C. La Borderie, "Phenomenes unilateraux dans un materiau endommageable: modelisation et application a l'analyse de structures en beton," Ph.D. dissertation, Univ. Paris 6, Paris, 1991.

[48] Associação Brasileira de Normas Técnicas, Projeto de Estruturas de Concreto - Procedimento, NBR 6118, 2014.

[49] P. Bartos, "Analysis of pull-out tests on fiber embedded in brittle matrices," J. Mater. Sci., vol. 15, no. 12, pp. 3122-3128, 1980.

[50] M. M. Lopes, "Substituição parcial de armadura de flexão por fibras de aço em vigas de concreto,” M.S. thesis, Dep. Eng. Estrut., Univ. Fed. Rio de Janeiro, Rio de Janeiro, 2005.

[51] W. M. Pereira Jr. and J. J. C. Pituba, “Análise paramétrica de vigas de concreto com fibras metálicas, in: Tecnologias em Pesquisa: Engenharias, J. J. C. Pituba and M. H. Stoppa, Eds., São Paulo: Blucher, 2017, pp. 349-364.

[52] D. L. Araújo, L. C. Carmo, F. G. T. Nunes, and R. D. Toledo Fo., "Computational modeling of steel fiber reinforced concrete beams subjected to shear," IBRACON Struct. Mater. J., vol. 3, pp. 68-94, 2010.

[53] A. R. Barros, P. C. C. Gomes, and A. S. R. Barboza, "Steel fibers reinforced self-compacting concrete - behavior to bending," IBRACON Struct. Mater. J., vol. 4, pp. 49-78, 2011.

[54] R. P. A. F. Pinto Lima, "Utilização de fibras metálicas com funções estruturais em estruturas de betão,” M.S. thesis, Fac. Eng. Porto, Porto, 2012.

Author contributions: J. J. C. Pituba: conceptualization, funding acquisition, supervision, writing, methodology, formal analysis; M. F. Pontes: writing, data curation, formal analysis; W. M. Pereira Junior: conceptualization, writing, methodology, data curation, formal analysis.

Editors: José Luiz Antunes de Oliveira e Sousa, Guilherme Aris Parsekian. 